\title{
Inhibition of Myo6 gene expression by co-expression of a mutant of transcription factor POU4F3 (BRN-3C) in hair cells
}

\author{
DENG-BIN MA $^{1 *}$, JIE CHEN $^{1 *}$, YANG XIA $^{1}$, GUANG-JIE ZHU $^{1}$, XIAO-FENG MA ${ }^{1}$, HAN ZHOU $^{1}$, \\ YA-JUN GU ${ }^{1}$, CHEN-JIE YU ${ }^{1}$, MIN-SHENG ZHU ${ }^{2}$, XIAO-YUN QIAN ${ }^{1}$ and XIA GAO ${ }^{1}$ \\ ${ }^{1}$ Nanjing Drum Tower Hospital, Nanjing University Medical College, Nanjing, Jiangsu 210008; \\ ${ }^{2}$ MOE Key Laboratory for Model Animal and Diseases Studies, Model Animal Research Center of Nanjing University, \\ Nanjing, Jiangsu 210061, P.R. China
}

Received June 21, 2013; Accepted February 3, 2014

DOI: $10.3892 / \mathrm{mmr} .2014 .1953$

\begin{abstract}
An eight-base pair (bp) deletion in the Pou $4 f 3$ gene in hair cells is associated with DFNA15, a hereditary form of hearing loss. To explore the pathological mechanisms underlying the development of DFNA15, the effect of the mutation in Pou 4 f3 on the activity of the myosin VI (Myo6) promoter, was investigated. The upstream regulatory sequence of Myo6 (2625 bp), consisting of an 1899 bp upstream sequence and a 727 bp intron 1 sequence, was amplified using polymerase chain reaction and subcloned into the pGL3-Basic vector expressing firefly luciferase. For verification of inserted fragments, plasmids were subjected to restriction analysis and then sequenced. HEK293T human embryonic kidney cells were transiently transfected with renilla luciferase-thymidine kinase vectors expressing Renilla luciferase and the Myo6 promoter-driven firefly luciferase expressing vectors along with pIRES2-enhanced green fluorescent protein (EGFP)-Pou $4 f 3$ (expressing wild-type Pou4f3) or pIRES2-EGFP-Pou4f3 (expressing the truncation mutant of Pou4f3). The relative luciferase activities were measured to determine the activity of the Myo6 promoter. The Myo6 promoter activity was not affected by co-expression of wild-type Pou $4 \mathrm{f} 3$, as indicated by the comparable relative luciferase activities in the presence of the pIRES2-EGFP-Pou $4 f 3$ and the empty control vectors. However, co-expression of mutated Pou $4 f 3$ significantly inhibited the activity of the Myo6 promoter to almost half of that of the control $(\mathrm{P}<0.001)$. The data suggests that mutated Pou 4 3 has a negative role in the promoter activity of Myo6,
\end{abstract}

Correspondence to: Dr Xiao-Yun Qian or Professor Xia Gao, Department of Otorhinolaryngology Head and Neck Surgery, Nanjing Drum Tower Hospital, 321 Zhongshan Road, Nanjing, Jiangsu 210061, P.R. China

E-mail: qxy522@163.com

E-mail: xiagao@aliyun.com

*Contributed equally

Key words: Pou4f3, Myo6, DFNA15, hair cell and by extension, the expression of myosin VI, and this may be an underlying mechanism of DFNA15 hearing loss.

\section{Introduction}

Hearing impairment is one of the most common types of genetic diseases, with an estimated prevalence of 1-3/1,000 newborns, at least half of which is attributed to genetic factors (1). One out of every 10 persons with a hearing impairment are carriers of mutant genes associated with deafness (1). Although not life-threatening, loss of hearing is a debilitating disorder which affects the life of patients in significant and occasionally devastating ways. Mutations in a large variety of genes have been identified as the cause of hereditary hearing loss. In 1998, Vahava et al (2) determined the molecular basis for an autosomal dominant progressive nonsyndromic hearing loss, DFNA15 (MIM 602459), in an Israeli Jewish family. A mutation in the Pou4f3 gene (encoding for the POU domain transcription factor Brn3c/Brn3.1) was described, in which an eight-base pair (bp) deletion in exon 2 results in the formation of a premature stop codon in the first helix of this transcription factor. The truncation of the Pou $4 f 3$ proteins affect their ability to bind and activate downstream targets (3). The mechanism by which the Pou4f3 mutation leads to DFNA15 hearing loss remains to be elucidated. In Pou $4 f 3^{-/-}$mice, the overall architecture of the cochlea is unaffected and hair cell markers are detected during early differentiation (4-6). However, hair cells in Pou $43^{-/-}$mice undergo progressive loss compared with those of wild-type mice, with a disorderly arrangement, and are misplaced among supporting cells $(6,7)$. Furthermore, the apical surface of hair cells in Pou $43^{-/-}$mice is devoid of stereocilia, or with fused, disorganized, and occasionally giant stereocilia (4-8).

Stereocilia are a type of organ-pipe-arrayed giant stiff microvilli on the free surface of hair cells, containing a parallel bundle of actin filaments at the core. Deletion or mutation of the genes Espn, Myo15, Myo6, and Myo7a accounts for the malformation of stereocilia (9-14). Myosin VI, an anchoring protein encoded by Myo6, may aid to hold down the membrane against surface tension forces and to anchor the apical hair cell membrane to the actin cytoskeleton of the cuticular plate, thus permitting the stereocilia to remain as separate entities. 
Disturbance of myosin VI may be implicated in the formation of fused and giant stereocilia, since inadequate anchoring of the apical membrane between stereocilia may result in the elevation of the membrane between adjacent stereocilia due to surface tension $(11,15,16)$.

These data suggest that Pou4f3 and Myo6 are essential for the development and maintenance of stereocilia. Mutation of either gene may lead to abnormal stereocilial structures and hearing impairment in humans and mice. To elucidate the pathological mechanisms that contribute to the development of DFNA15, a form of hereditary deafness in humans, the Myo6 promoter-driven expression in wild-type and mutant cells, carrying an eight-bp deletion in exon 2 of Pou $4 f 3$, were investigated in the present study using an in vitro mouse cell-based model.

\section{Materials and methods}

Plasmids, strains and cell lines. The pGL3-Basic, renilla luciferase-thymidine kinase (pRL-TK) control reporter, pIRES2-enhanced green fluorescent protein (EGFP)-Pou $4 f 3$ (wild-type), and pIRES2-EGFP-Pou4f3 (8-bp deletion in exon 2) vectors, C57/B6 mouse DNA, E. Coli DH5a competent cells, and the HEK293T human embryonic kidney (293T) cells used in the present study were kindly provided by Min-Sheng Zhu, Model Animal Research Center of Nanjing University (Nanjing, China).

Primer design and polymerase chain reaction (PCR) amplification. The promoter sequence of mouse Myo6 was inferred from that of humans and consisted of a total of $2625 \mathrm{bp}$. The 1899 bp upstream and $727 \mathrm{bp}$ intron 1 sequences of the mouse Myo6 gene were analyzed using Vector NTI 10 software (Invitrogen Life Technologies, Carlsbad, CA, USA), which was also used to design primers for amplification of the Myo6 promoter. The sequences of the forward and reverse primers were 5'-(ACGCGT)TTTAAAAACTAAAGTTCC CTTTCAG-3' and 5'-(AAGCTT)CAGTATCTCCACATT GGGAT-3', respectively, where ACGCGT and AAGCTT are restriction sites for $M l u \mathrm{I}$ and HindIII, respectively. Primers were synthesized by GenScript Corporation (Nanjing, China). The Myo6 promoter region was amplified from the C57/B6 mouse tail DNA with high-fidelity polymerase ExTaq using the above mentioned primers. The PCR conditions were as follows: An initial denaturation step of $98^{\circ} \mathrm{C}$ for $5 \mathrm{~min}$; followed by 30 cycles at $98^{\circ} \mathrm{C}$ for $10 \mathrm{sec}, 60^{\circ} \mathrm{C}$ for $15 \mathrm{sec}$ and $72^{\circ} \mathrm{C}$ for $3.5 \mathrm{~min}$, followed by a final elongation step at $72^{\circ} \mathrm{C}$ for $10 \mathrm{~min}$ and maintenance at $16^{\circ} \mathrm{C}$ until the reactions were completed. Amplified products were mixed with $0.5 \mu 1 \mathrm{Taq}$ enzyme and incubated at $72^{\circ} \mathrm{C}$ for $15 \mathrm{~min}$ followed by elongation at $4^{\circ} \mathrm{C}$ to add an A-tail directly to the $3^{\prime}$-ends of the blunt-ended DNA fragment. Products were analyzed by electrophoresis on $0.8 \%$ agarose gels. Target bands were excised from the gel and the DNA was recovered using a DNA Gel Extraction Kit (Corning Life Sciences-Axygen Inc., Union City, CA, USA).

Plasmid constructs. The PCR products and pGL3-Basic vector were excised using MluI and HindIII (Takara Bio, Inc., Shiga, Japan) restriction enzymes. PCR products were ligated

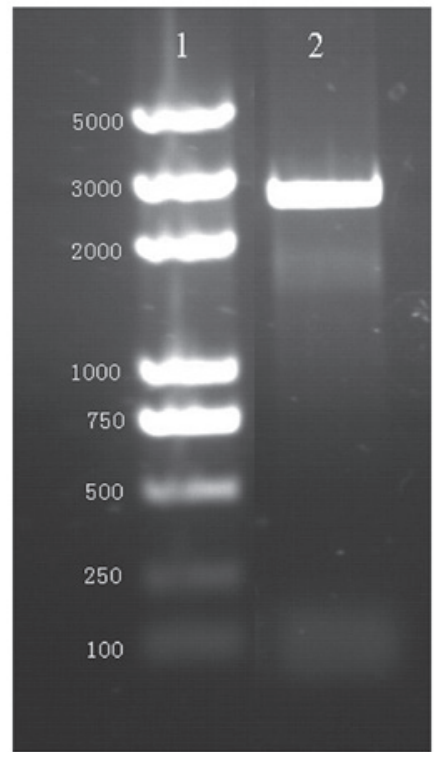

Figure 1. Polymerase chain reaction amplification of Myo6 from mouse tail DNA. Lanes 1, Trans2K Plus DNA marker, with sizes indicated in bp on the left; and 2, amplified Myo6, 2625 bp. Myo6, myosin IV promoter.

into the pGL3-Basic vectors containing the luciferase reporter gene using T4 DNA ligase (Takara Bio, Inc.). Competent E. coli DH5 $\alpha$ cells were transformed with pGL3-Basic-Myo6 promoter vectors, plated on Luria-Bertani (LB) medium containing ampicillin, and the plates were incubated at $37^{\circ} \mathrm{C}$ for 12-20 h. Individual colonies were selected and grown in the liquid culture medium containing ampiccilin overnight. Plasmids were extracted using the AxyPrep Plasmid Miniprep Kit (Corning Life Sciences-Axygen, Inc.) and digested with $M l u \mathrm{I}$ and HindIII, followed by purification of the inserted sequences for further sequencing by GenScript Corporation.

Cell culture. $293 \mathrm{~T}$ cells were grown and maintained in Dulbecco's modified Eagle medium (Gibco-BRL, Carlsbad, CA, USA) containing $10 \%$ fetal bovine serum (PAA Laboratories, Cölbe, Germany) supplemented with $100 \mathrm{IU} / \mathrm{ml}$ penicillin and $100 \mathrm{mg} / \mathrm{l}$ streptomycin at $37^{\circ} \mathrm{C}$ in an atmosphere of $5 \% \mathrm{CO}_{2}$.

Plasmid transfection and luciferase reporter assays. The day prior to transfection, 293T cells were suspended in fresh medium and plated in 96-well plates at a density of $2 \times 10^{4}$ cells/well. When the cells reached $70 \%$ confluency, they were transfected with $50 \mathrm{ng}$ pGL3-Basic-Myo6 promoter and $0.5 \mathrm{ng} \mathrm{pRL}-\mathrm{TK}$ (internal control), along with either pIRES2-EGFP, pIRES2-EGFP-Pou4f3 (wild-type), or pIRES2-EGFP-Pou4f3 (8-bp deletion in exon 2), using the Lipofectamine ${ }^{\mathrm{TM}} 2000$ Transfection Reagent (Invitrogen Life Technologies) according to the manufacturer's instructions. The total amount of plasmid DNA was maintained at $200 \mathrm{ng}$ in each well. The cells were harvested and lyzed $24 \mathrm{~h}$ post-transfection. Firefly and Renilla luciferase activities were determined with the Dual-Luciferase Reporter Assay System in a GloMax96 luminescence reader (both from Promega, Madison, WI, USA) according to the manufacturer's instructions. Relative luciferase activity was expressed as the ratio 


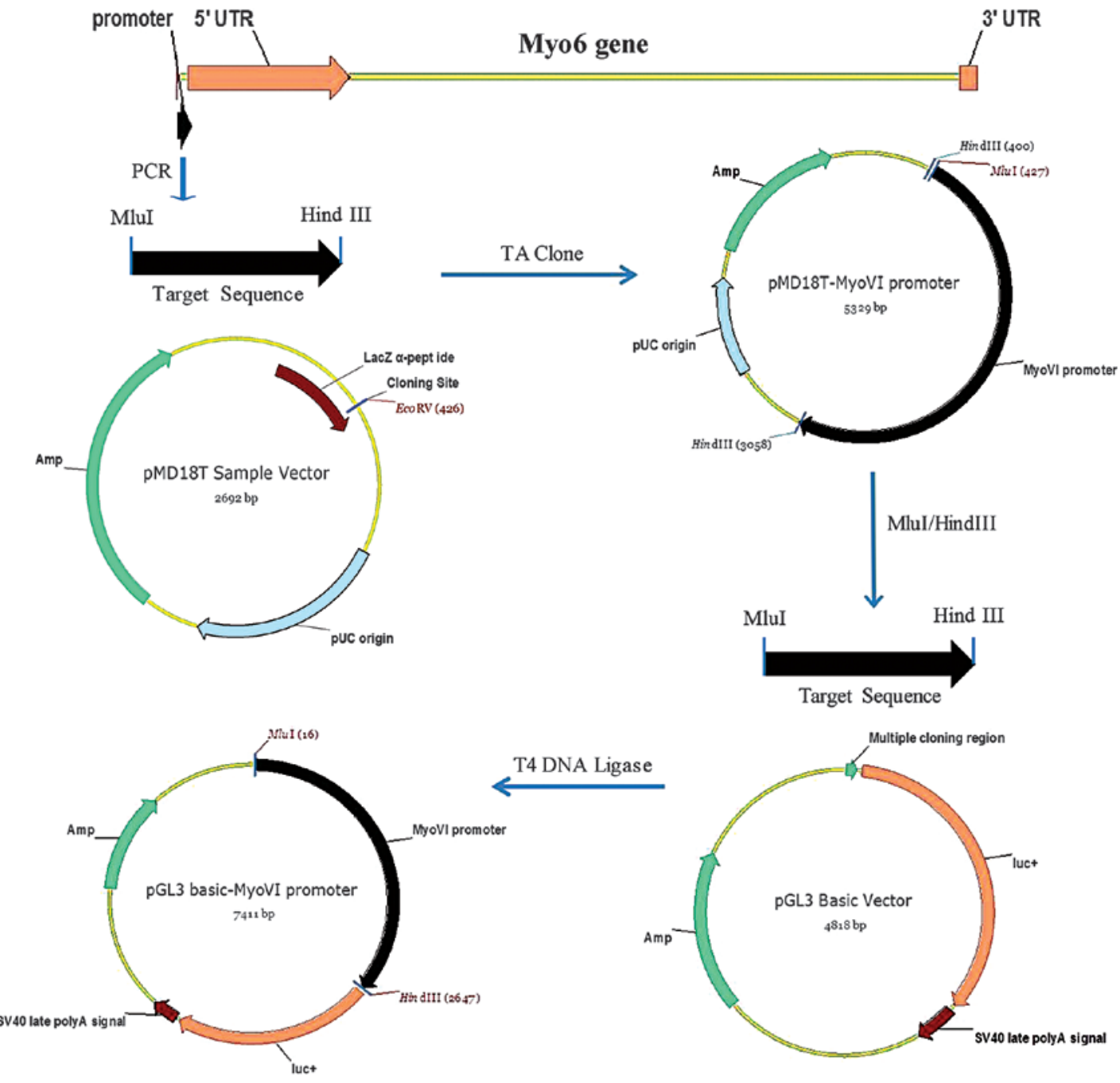

Figure 2. Schematic diagram of the strategy for constructing the Myo6 reporter-driven luciferase expression vector. The promoter sequence of mouse Myo6 was inferred and amplified from mouse tail genomic DNA using PCR. Purified target fragments were subcloned into pMD-18T. For verification of the length and orientation of the inserted fragments, the plasmids were digested with $M l u \mathrm{I}$ and $H i n \mathrm{dIII}$ and then sequenced. Finally, fragments whose sequences were verified by sequencing analysis were ligated into the pGL3-Basic vectors using T4 DNA ligase to construct the pGL3-Basic-Myo6 promoter vector. Myo6, myosin IV promoter; UTR, untranslated region; PCR, polymerase chain reaction; luc, luciferase; polyA, polyadenylation.

of firefly luciferase activity to the Renilla luciferase activity in each sample. All values were obtained from at least three independent repetitions of the transfection, with six wells for each transfection mixture/sample in every experiment.

Statistical analysis. Data analysis was performed using the SPSS 16.0 statistical software (SPSS Inc., Chicago, IL, USA). The Student's t-test was used for comparing means between groups. $\mathrm{P}<0.05$ was considered to indicate a statistically significant difference.

\section{Results}

Myo6 promoter amplification. PCR was performed using primers with restriction sites. Gel electrophoresis analysis revealed the presence of a $2625 \mathrm{bp}$ fragment in the PCR product, as expected (Fig. 1). Non-specific amplification was not detected (Fig. 1). Furthermore, the sequencing analysis confirmed that the sequence of the amplified Myo6 promoter was consistent with that of the template.
Construction and confirmation of GL3-Basic-Myo6 promoter vectors. The Myo6 promoter-driven luciferase reporter construct, pGL3-Basic-Myo6 promoter, was constructed as described in the materials and methods section (Fig. 2). To verify the sequences introduced into the pGL3-Basic-Myo6 promoter vector, the plasmid DNAs were digested with $M l u \mathrm{I}$ and HindIII and the DNA fragments were re-introduced into the same vectors, i.e., pGL3-Basic vector, followed by sequencing analysis. The sequences were confirmed to be correct and devoid of any mutations, demonstrating that the Myo6 promoter was successfully inserted into pGL3-Basic vectors (Fig. 3).

Dual luciferase reporter assay. The activity of the Myo6 promoter in $293 \mathrm{~T}$ cells was assayed using the pGL3-Basic Myo6 promoter reporter, in the presence of wild-type Pou 43 or a truncated mutant of Pou $4 f 3$, with the dual luciferase assay system. The relative luciferase activity was expressed as the ratio of firefly luciferase activity to Renilla luciferase activity to evaluate the effect of Pou $4 f 3$ on the promoter 


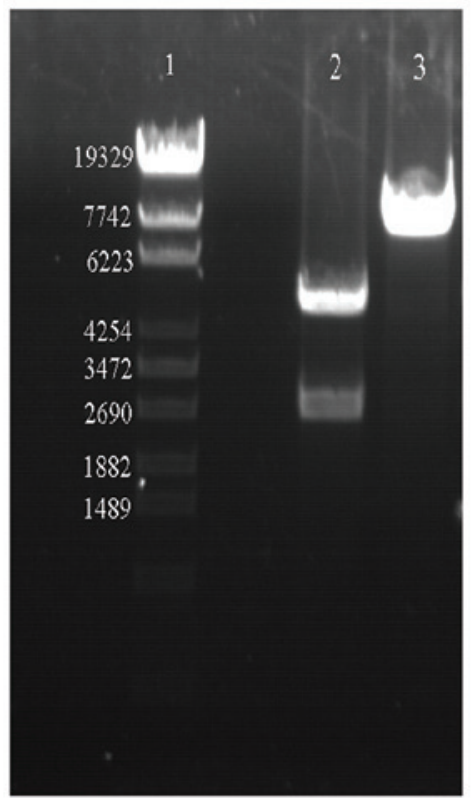

B

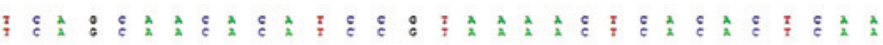

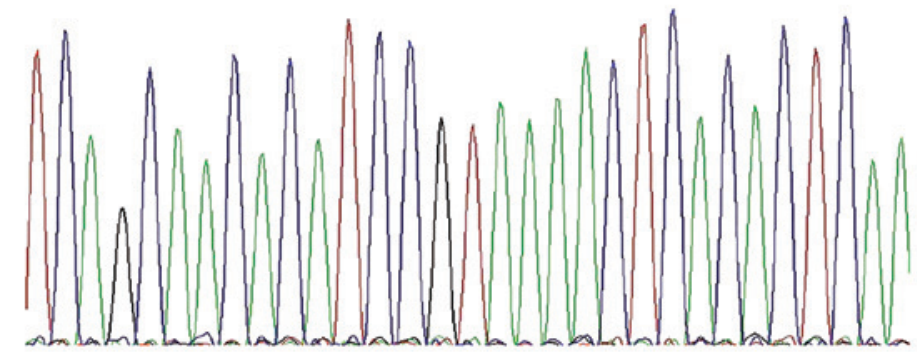

:

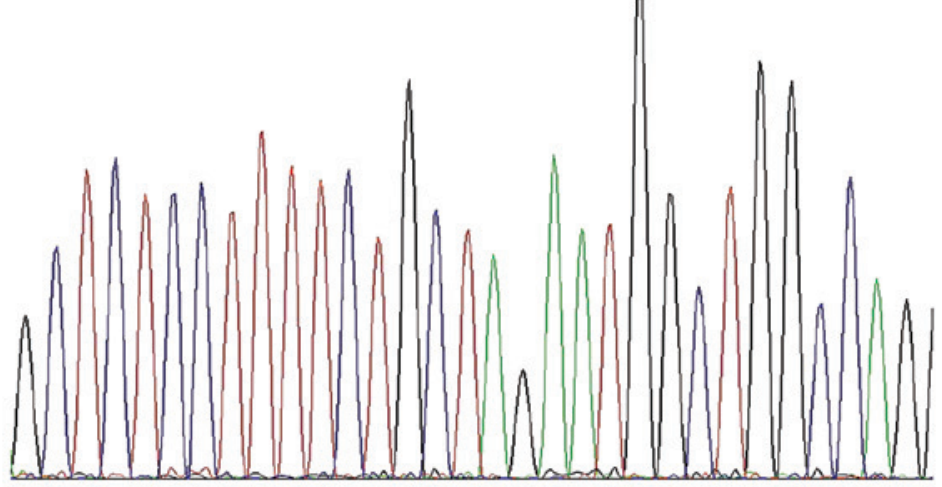

Figure 3. Identification of recombinant expression vector by restriction enzyme analysis and the inserted sequences by sequencing analysis. (A) Lanes 1 , $\lambda$-EcoT14 I digest DNA Maker, with sizes indicated in bp on the left; 2, restriction analysis with MluI and HindIII, the upper 4818-bp band corresponds to the pGL3-Basic vector, the lower 2625 bp band corresponds to the Myo6 promoter-containing target fragment; and 3, restriction enzyme analysis by HindIII, the linearized 7411-bp pGL3-Basic-Myo6 promoter vector. (B) Bidirectional sequencing for the insert sequences, the sequences were confirmed to be correct and devoid of any mutations. Myo6, myosin IV promoter.

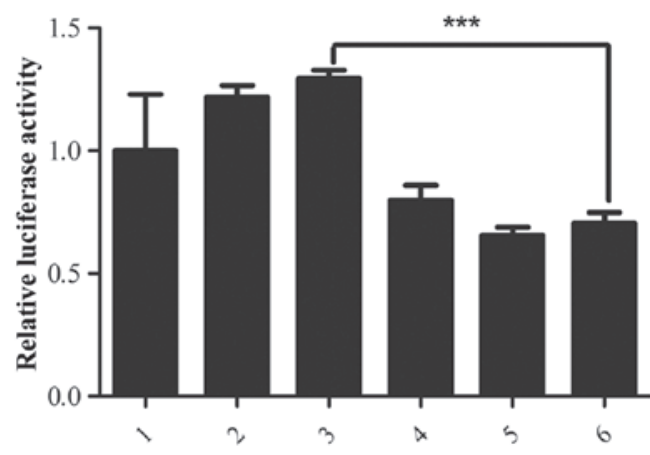

Figure 4. Regulation of the Myo6 promoter by Pouf $4 \mathrm{f} 3$ as assessed using a luciferase reporter assay. $293 \mathrm{~T}$ cells were transfected with the indicated combinations of vectors and the relative luciferase activity was measured to evaluate the Myo6 promoter activity. 1, pIRES2-EGFP empty vector, the ratio of firefly/Renilla luciferase activities for this empty vector, used as the control, was normalized to 1.0 and the relative luciferase activity in all other samples is calculated following normalization to the control value; 2-3, 100 and $150 \mathrm{ng}$ of pIRES2-EGFP-Pouf4f3 (wild-type), respectively; 4-6, 50, 100 and $150 \mathrm{ng}$ of pIRES2-EGFP-Pouf4f3 (8-bp deletion in exon 2), respectively. No difference between in relative luciferase activity was observed in cells transfected with the wild-type Pouf4f3-expressing plasmid and the control In contrast, co-transfection with the mutant Pouf $4 f 3$-expressing plasmid significantly inhibited the expression of luciferase from the Myo6 promoter, reducing the relative luciferase activity to almost half of that of the control $(\mathrm{P}<0.001) .{ }^{* * *} \mathrm{P}<0.001$, vs. control. Myo6, myosin IV promoter; EGSP, enhanced green fluorescent protein.

activity of Myo6. The relative luciferase activity of cells expressing wild-type Pou $4 f 3$ was comparable to that of the control, wherein the empty vector was co-transfected with the luciferase reporters. Co-transfection of the construct expressing mutated Pou $4 \mathrm{f} 3$ downregulated the expression of luciferase from the Myo6 promoter to almost half of that of the control ( $\mathrm{P}<0.001$; Fig. 4), indicating that mutated Pou $4 \mathrm{f} 3$ has a negative role in the expression of Myo6. These data indicate that the inhibition of expression of $M y \circ 6$ in the presence of the mutated Pou $4 f 3$ may be an underlying mechanism of DFNA15 hearing loss.

\section{Discussion}

Stereocilia of hair cells perform the process of auditory transduction. They receive mechanical inputs derived from airborne sound waves and transduce these signals into electrical responses that are then relayed to the brain for interpretation. Only stereocilia, arranged in rows of increasing height, are capable of converting mechanical activity to electrical activity (17-19). Damage to, or deterioration of the staircase-like arrangement of stereocilia accounts for hearing loss or balance disorders $(15,20,21)$. With the help of transgenic and knock-out mouse models of human hearing loss (22), a variety of genes responsible for inner ear development and deafness, including genes encoding transcription factors, actins, ion channels, membrane proteins, and structural proteins, have been identified $(2,21,23,24)$. Specifically, transcription factors including Math1 (25-28) and POU4f3 have been shown to be crucial for hair cell development, differentiation, maturation and maintenance. Structural proteins, including Myo6 and Myo7a are important for the stability of the structure and function of stereocilia. 
The POU-domain family of transcription factors is widely expressed in the nervous system. For example, Pou 4f1, 2 and 3 are essential for the development of sensory ganglion, retinal ganglion and hair cells, respectively (29-33). Pou4f3 (also known as Brn3.1 and Brn3c), an important transcription factor of the POU-domain family, specifically binds to a 9-bp recognition element, ATAATTAAT to activate downstream gene expression and thus cell development $(34,35)$. Brn3c-/- mice deficient in Pou $4 f 3$ are hearing impaired and exhibit vestibular dysfunction. Furthermore, the hair cells fail to mature and stereociliary bundles are formed or only malformed and disorganized stereocilia exist (6-8,36).

Mutation of unconventional myosins, including myosins VIIa, VI, Ic, and XV, have been shown to be associated with deafness. Normally present on cilia and actin-rich microvilli, including the stereocilia on mammalian hair cells, unconventional myosins are required for the cohesion and structural integrity of the bundle (11,37-39). Myosin VI, encoded by Myo6, is expressed in the inner and outer hair cells of mouse cochlea, concentrating in the actin-rich cuticular plate associated with stereociliary rootlets, pericuticular necklaces, and cytoplasm $(11,15)$. As an anchoring protein, myosin VI may help anchor the membrane against surface tension forces and to anchor the apical hair cell membrane to the actin cytoskeleton of the cuticular plate, thus permitting the stereocilia to remain as separate entities. Myosin VI is crucial for the motility and shape change of hair cells during the development of stereocilia, and mutation of myosin VI results in the formation of giant stereociliary bundles and degenerated hair cells (11).

The luciferase reporter assay system is widely used to investigate the interaction between cis-acting regulatory elements, including promoters, enhancers, silencers and trans-acting regulatory proteins. This reporter assay has become the choice of the majority of investigations due to the advantages of rapidity, reliability and sensitivity. In the present study, the Myo6 promoter was successfully inserted into an expression vector and the Myo6 promoter-driven luciferase reporter construct was transiently transfected into human embryonic kidney 293 T cells, along with expression vectors carrying wild-type and mutated Pou $4 f 3$ using liposomes. The present study showed no differences between the Myo6 promoter activity in cells expressing the wild-type Pou $4 f 3$ and the control cells. However, co-transfection with the mutated Pou4f3-expressing construct significantly inhibited the Myo6 promoter activity to almost half of that of the control, indicating that mutated Pou $4 f 3$ has a negative role in the regulation of Myo6 expression. The data suggest that the inhibition of the Myo6 promoter and consequently the expression of myosin VI due to mutation of Pou $4 f 3$ may be an underlying mechanism of DFNA15. These data provide insights into the molecular basis of hearing impairment in DFNA15 hearing loss and suggest that loss of expression from the Myo6 promoter may explain, at least in part, the hearing loss phenotype in the presence of the Pou $4 f 3$ truncation mutation.

\section{Acknowledgements}

The authors would like to thank Professor Minsheng Zhu, Drs Yajing Peng, Chen Chen, Chenghai Zhang, Yanning Qiao, Caiping Chen and Pei Wang from the Model Animal Research
Center of Nanjing University in China. The present study was supported by grants from the National Natural Science Foundation of China (nos 81371090 and 30973302), and the Key Project supported by Medical Science and Technology Development Foundation, Nanjing Department of Health (no. 201108019).

\section{References}

1. Piatto VB, Nascimento EC, Alexandrino F, Oliveira CA, Lopes AC, Sartorato EL and Maniglia JV: Molecular genetics of non-syndromic deafness. Braz J Otorhinolaryngol. 71: 216-223, 2005.

2. Vahava O, Morell R, Lynch ED, Weiss S, Kagan ME, Ahituv N, Morrow JE, Lee MK, Skvorak AB, Morton CC, Blumenfeld A, Frydman M, Friedman TB, King MC and Avraham KB: Mutation in transcription factor POU4F3 associated with inherited progressive hearing loss in humans. Science 279: 1950-1954, 1998.

3. Weiss S, Gottfried I, Mayrose I, Khare SL, Xiang M, Dawson SJ and Avraham KB: The DFNA15 deafness mutation affects POU4F3 protein stability, localization, and transcriptional activity. Mol Cell Biol 23: 7957-7964, 2003.

4. Gerrero MR, McEvilly RJ, Turner E, Lin CR, O'Connell S, Jenne KJ, Hobbs MV and Rosenfeld MG: Brn-3.0: a POU-domain protein expressed in the sensory, immune, and endocrine systems that functions on elements distinct from known octamer motifs. Proc Natl Acad Sci USA 90: 10841-10845, 1993.

5. Ninkina NN, Stevens GE, Wood JN and Richardson WD: A novel Brn3-like POU transcription factor expressed in subsets of rat sensory and spinal cord neurons. Nucleic Acids Res 21: 3175-3182, 1993.

6. Xiang M, Gan L, Zhou L, Klein WH and Nathans J: Targeted deletion of the mouse POU domain gene Brn-3a causes selective loss of neurons in the brainstem and trigeminal ganglion, uncoordinated limb movement, and impaired suckling. Proc Natl Acad Sci USA 93: 11950-11955, 1996.

7. Xiang M, Gan L, Li D, Chen ZY, Zhou L, O'Malley BW Jr, Klein $\mathrm{W}$ and Nathans J: Essential role of POU-domain factor Brn-3c in auditory and vestibular hair cell development. Proc Natl Acad Sci USA 94: 9445-9450, 1997.

8. Xiang M, Gan L, Li D, Zhou L, Chen ZY, Wagner D, O'Malley BW Jr, Klein W and Nathans J: Role of the Brn-3 family of POU-domain genes in the development of the auditory/vestibular, somatosensory, and visual systems. Cold Spring Harb Symp Quant Biol 62: 325-336, 1997.

9. Zheng L, Sekerková G, Vranich K, Tilney LG, Mugnaini E and Bartles JR: The deaf jerker mouse has a mutation in the gene encoding the espin actin-bundling proteins of hair cell stereocilia and lacks espins. Cell 102: 377-385, 2000.

10. Karolyi IJ, Probst FJ, Beyer L, Odeh H, Dootz G, Cha KB, Martin DM, Avraham KB, Kohrman D, Dolan DF, Raphael Y and Camper SA: Myo15 function is distinct from Myo6, Myo7a and pirouette genes in development of cochlear stereocilia. Hum Mol Genet 12: 2797-2805, 2003.

11. Self T, Sobe T, Copeland NG, Jenkins NA, Avraham KB and Steel KP: Role of myosin VI in the differentiation of cochlear hair cells. Dev Biol 214: 331-341, 1999.

12. Holme RH and Steel KP: Stereocilia defects in waltzer (Cdh23), shaker1 (Myo7a) and double waltzer/shaker1 mutant mice. Hear Res 169: 13-23, 2002.

13. Boëda B, El-Amraoui A, Bahloul A, Goodyear R, Daviet L, Blanchard S, Perfettini I, Fath KR, Shorte S, Reiners J, Houdusse A, Legrain P, Wolfrum U, Richardson G and Petit C: Myosin VIIa, harmonin and cadherin 23, three Usher I gene products that cooperate to shape the sensory hair cell bundle. EMBO J 21: 6689-6699, 2002.

14. Belyantseva IA, Boger ET, Naz S, Frolenkov GI, Sellers JR, Ahmed ZM, Griffith AJ and Friedman TB: Myosin-XVa is required for tip localization of whirlin and differential elongation of hair-cell stereocilia. Nat Cell Biol 7: 148-156, 2005.

15. Hertzano R, Shalit E, Rzadzinska AK, Dror AA, Song L, Ron U, Tan JT, Shitrit AS, Fuchs H, Hasson T, Ben-Tal N, Sweeney HL, de Angelis MH, Steel KP and Avraham KB: A Myo6 mutation destroys coordination between the myosin heads, revealing new functions of myosin VI in the stereocilia of mammalian inner ear hair cells. PLoS Genet 4: e1000207, 2008. 
16. Avraham KB, Hasson T, Sobe T, Balsara B, Testa JR, Skvorak AB, Morton CC, Copeland NG and Jenkins NA: Characterization of unconventional Myo6, the human homologue of the gene responsible for deafness in Snell's waltzer mice. Hum Mol Genet 6: 1225-1231, 1997.

17. Dallos P: Peripheral mechanisms of hearing. In: Comprehensive Physiology. John Wiley \& Sons, Inc., 2011.

18. Roberts WM, Howard J and Hudspeth AJ: Hair cells: transduction, tuning, and transmission in the inner ear. Annu Rev Cell Biol 4: 63-92, 1988.

19. Fettiplace R and Fuchs PA: Mechanisms of hair cell tuning. Annu Rev Physiol 61: 809-834, 1999.

20. Frolenkov GI, Belyantseva IA, Friedman TB and Griffith AJ: Genetic insights into the morphogenesis of inner ear hair cells. Nat Rev Genet 5: 489-498, 2004.

21. Zhu GJ, Wang F, Chen C, Xu L, Zhang WC, Fan C, Peng YJ, Chen J, He WQ, Guo SY, Zuo J, Gao X and Zhu MS: Myosin light-chain kinase is necessary for membrane homeostasis in cochlear inner hair cells. PLoS One 7: e34894, 2012.

22. Avraham KB: Mouse models for deafness: lessons for the human inner ear and hearing loss. Ear Hear 24: 332-341, 2003.

23. Peters LM, Anderson DW, Griffith AJ, Grundfast KM, San Agustin TB, Madeo AC, Friedman TB and Morell RJ: Mutation of a transcription factor, TFCP2L3, causes progressive autosomal dominant hearing loss, DFNA28. Hum Mol Genet 11: 2877-2885, 2002.

24. Liu XZ, Ouyang XM, Xia XJ, Zheng J, Pandya A, Li F, Du LL, Welch KO, Petit C, Smith RJ, Webb BT, Yan D, Arnos KS, Corey D, Dallos P, Nance WE and Chen ZY: Prestin, a cochlear motor protein, is defective in non-syndromic hearing loss. Hum Mol Genet 12: 1155-1162, 2003.

25. Chen P, Johnson JE, Zoghbi HY and Segil N: The role of Math1 in inner ear development: Uncoupling the establishment of the sensory primordium from hair cell fate determination. Development 129: 2495-2505, 2002.

26. Bermingham NA, Hassan BA, Price SD, Vollrath MA Ben-Arie N, Eatock RA, Bellen HJ, Lysakowski A and Zoghbi HY: Math1: an essential gene for the generation of inner ear hair cells. Science 284: 1837-1841, 1999.

27. Zine A, Aubert A, Qiu J, Therianos S, Guillemot F, Kageyama R and de Ribaupierre F: Hes1 and Hes5 activities are required for the normal development of the hair cells in the mammalian inner ear. J Neurosci 21: 4712-4720, 2001.

28. Kawamoto K, Ishimoto S, Minoda R, Brough DE and Raphael Y: Math1 gene transfer generates new cochlear hair cells in mature guinea pigs in vivo. J Neurosci 23: 4395-4400, 2003.
29. Eng SR, Lanier J, Fedtsova N and Turner EE: Coordinated regulation of gene expression by Brn3a in developing sensory ganglia. Development 131: 3859-3870, 2004.

30. Huang EJ, Liu W, Fritzsch B, Bianchi LM, Reichardt LF and Xiang M: Brn3a is a transcriptional regulator of soma size, target field innervation and axon pathfinding of inner ear sensory neurons. Development 128: 2421-2432, 2001.

31. Badea TC, Cahill H, Ecker J, Hattar S and Nathans J: Distinct roles of transcription factors brn $3 \mathrm{a}$ and brn $3 \mathrm{~b}$ in controlling the development, morphology, and function of retinal ganglion cells. Neuron 61: 852-864, 2009.

32. Liu W, Khare SL, Liang X, Peters MA, Liu X, Cepko CL and Xiang M: All Brn3 genes can promote retinal ganglion cell differentiation in the chick. Development 127: 3237-3247, 2000.

33. Sage C, Huang M, Vollrath MA, Brown MC, Hinds PW, Corey DP, Vetter DE and Chen ZY: Essential role of retinoblastoma protein in mammalian hair cell development and hearing. Proc Natl Acad Sci USA 103: 7345-7350, 2006.

34. Xiang M, Zhou L, Macke JP, Yoshioka T, Hendry SH, Eddy RL, Shows TB and Nathans J: The Brn-3 family of POU-domain factors: primary structure, binding specificity, and expression in subsets of retinal ganglion cells and somatosensory neurons. J Neurosci 15: 4762-4785, 1995.

35. Xiang M, Gao WQ, Hasson T and Shin JJ: Requirement for Brn-3c in maturation and survival, but not in fate determination of inner ear hair cells. Development 125: 3935-3946, 1998.

36. Keithley EM, Erkman L, Bennett T, Lou L and Ryan AF: Effects of a hair cell transcription factor, Brn-3.1, gene deletion on homozygous and heterozygous mouse cochleas in adulthood and aging. Hear Res 134: 71-76, 1999.

37. Anderson DW, Probst FJ, Belyantseva IA, Fridell RA, Beyer L, Martin DM, Wu D, Kachar B, Friedman TB, Raphael Y and Camper SA: The motor and tail regions of myosin XV are critical for normal structure and function of auditory and vestibular hair cells. Hum Mol Genet 9: 1729-1738, 2000.

38. Holt JR, Gillespie SK, Provance DW, Shah K, Shokat KM, Corey DP, Mercer JA and Gillespie PG: A chemical-genetic strategy implicates myosin-1c in adaptation by hair cells. Cell 108: 371-381, 2002

39. Kros CJ, Marcotti W, van Netten SM, Self TJ, Libby RT, Brown SD, Richardson GP and Steel KP: Reduced climbing and increased slipping adaptation in cochlear hair cells of mice with Myo7a mutations. Nat Neurosci 5: 41-47, 2002. 